\title{
GENDER EARNING DIFFERENCES IN THE EUROPEAN UNION MEMBER STATES
}

Dorota Witkowska, Department of Econometrics and Statistics WULS-SGGW, Warsaw, Poland Krzysztof Kompa, Department of Econometrics and Statistics WULS-SGGW, Warsaw, Poland Aleksandra Matuszewska-Janica, Dep. of Econometrics and Statistics WULS-SGGW, Warsaw, Poland

dx.doi.org/10.18374/EJM-13-4.10

\begin{abstract}
â€œEqual pay for equal workâ€ is one of the fundamental principles of the European Union. However, statistical surveys show that in 2011 in EU countries the gender pay gap was 16\% on average. The paper reports the recent investigation regarding gender disparities in the labor market. The main aim of our study is to identify factors affecting gender earning gapin the European Union member states. Research is conducted employing Structure of Earning Survey 2006 metadata.
\end{abstract}

Keywords: labor market, disparity, gender pay gap. JEL J16, J71 